trustworthiness of the study was examined using Lincoln and Guba (1985) principles.

Results Seventeen health care workers participated in our study. There are five main themes generated, including (1) Emotional loading: shock and collapse, fear of being seroconverted to infectious diseases, worry about family members, and damage of the professional image. (2) Disappointment on the working environment: lack of manpower support, feel isolated and helpless. (3) Disapproving eyes: invasion of privacy, fear of being labelled. (4) Impact on life: feelings of life-threatening, prophylaxis of physical discomfort, impact on professional ambitions. (5) Self-adjustment: efforts to recover from the event.

Conclusions A needlestick injury not only causes risk of infection, but has great psychosocial impact to the victims. Intervention should cover psychosocial support to the health care workers in addition to prophylaxis of infection.

\section{LUNG CANCER AND EXPOSURE TO BENZENE, TOLUENE AND XYLENE: RESULTS FROM TWO CASE-CONTROL STUDIES IN MONTREAL}

David Vizcaya, Marcela Rivera, Jerome Lavoue, Jack Siemiatycki. University of Montreal Hospital Research Centre (CRCHUM), Montreal, Quebec, Canada

\subsection{6/oemed-2014-102362.283}

Objectives We aimed to evaluate the risks of lung cancer associated with exposure to benzene, to toluene and to xylene.

Method Two population-based case-control studies conducted in Montreal included 1896 lung cancer cases and 1908 controls. Study I was conducted in 1980-1986, and study II in 19952001. Occupational exposures were assessed using a combination of subject-reported job history and expert assessment. Participants provided information on sociodemographic characteristics and smoking history. Using logistic regression, we evaluated the risk of lung cancer due to the exposure to each agent.

Results Lifetime exposure prevalence ranged from 12\% for xylene to $20 \%$ for benzene in study I, and $11 \%$ for xylene to $15 \%$ for benzene in study II. In both studies, $25 \%$ of the participants were exposed to benzene, toluene or xylene. Pooling studies, the odds ratios and 95\% confidence interval (OR) for everexposure to any of the evaluated agents was $1.2(1.0-1.4)$. In analyses including all subjects but only one agent at a time in the models, ORs were around 1.2-1.3 for each agent. When we excluded subjects ever exposed to two or three of these agents, none of the agents showed excess risk. Being ever exposed to all three agents was associated with lung cancer (OR: 1.3; 1.0-1.6). Attempts to estimate ORs for each agent while controlling for the two others resulted in co-linearity.

Conclusions We found no clear indications of an association between lung cancer and exposure to toluene or xylene, but there was some evidence for an association with benzene.

\section{ACUTE EFFECTS OF OCCUPATIONAL NOISE EXPOSURE ON 24-HOUR AMBULATORY CARDIAC PARAMETERS IN WORKERS}

${ }^{1}$ Ta-Yuan Chang, ${ }^{1}$ Ya-Yun Wu, ${ }^{1}$ Ven-Shing Wang, ${ }^{2}$ Chang-Chuan Chan, ${ }^{3}$ Chiu-Shong Liu. ${ }^{1}$ China Medical University, Taichung, Taiwan; ${ }^{2}$ National Taiwan University, Taipei, Taiwan; ${ }^{3}$ China Medical University Hospital, Taichung, Taiwan

10.1136/oemed-2014-102362.284
Objectives Exposure to noise has been associated with cardiovascular disease, but the mechanism related to cardiac activity is unknown. This repeated-measure study aimed to investigate effects of occupational noise exposure on 24-hour ambulatory cardiac parameters among aviation industry workers.

Method We recruited 75 volunteers in an aircraft-manufacturing industrial cohort in 2009. Individual noise exposure and personal cardiac parameters, including left ventricular contractility (LVC) and stroke volume (SV), were measured simultaneously over $24 \mathrm{~h}$ on working and non-working days. Linear mixedeffects regressions were used to determine transient and sustained effects on ambulatory LVC and SV among high-exposure ( $\geq 80$ A-weighted decibel [dBA]), low-exposure $(<80 \mathrm{dBA})$ and office workers by controlling for potential confounders.

Results Per 1-dBA increase was significantly associated with the transient effects of -1.50 (95\% confidence interval [CI]: -2.166 , $-1.024) \mathrm{ml} /$ beat in SV and $-1.75(-2.95,-1.03) \mathrm{L} / \mathrm{sec}$ in LVC at work on working day only among high-exposure workers. Such decreasing effects on SV $(-1.18[-2.86,-1.09] \mathrm{ml} /$ beat $)$ and LVC $(-2.22,[-4.43,-1.11] \mathrm{L} / \mathrm{sec})$ still persisted in the 30 -min timelagged occupational noise exposure. We also found that 1-dBA increment in 24-hour average noise exposure was significantly associated with a sustained decrease of $-1.19(-1.25,-1.13) \mathrm{ml} /$ beat in SV on working day among high-exposure workers. No significant effects were found among other groups on working day and among all groups on non-working day.

Conclusions Occupational noise exposure may have acute effects on 24-hour ambulatory cardiac parameters among workers. Such effects may be associated with the development of cardiovascular disease.

\section{ASSOCIATION BETWEEN THE OXIDATIVE STRESS AND RENAL FUNCTION WITH EXPOSURE TO TCE IN UNDERGROUND WATER}

Cing-Jheng Li. Inst of Environ. and Occup. Health Sciences, Taipei, Taiwan

10.1136/oemed-2014-102362.285

Objectives Our study is to assess association between the oxidative stress and renal function with exposure to TCE in underground water.

Method 579 questionnaires and 180 urine specimens were voluntarily taken from 1165 residents. Information of exposure to TCE in underground water was interviewed questionnaire and urinary trichloroacetic acid (TCA) levels by gas chromatography (GC)-FID. Urinary malondialdehyde (MDA) and N-Acetyl- $\beta$-D-Glucosaminidase (NAG) were taken as indicators of oxidative stress and renal function to show health effects with exposure to TCE in underground water.

Results Consumption of underground water was positively correlated with urinary TCA levels $(\mathrm{r}=0.554)$. Urinary TCA levels was positively associated with NAG levels $(r=0.180)$, but it negatively associated with MDA levels $(r=-0.193)$. Urinary TCA levels classified into three groups was dose-dependent positively with NAG levels, indicating exposure to TCE in underground water is results in the abnormal renal function. However, TCA levels were dose-dependent negatively with MDA levels which explained by that many factors of life-style may affect to urinary MDA levels.

Conclusions Using TCA in urine is suitably used as a biological indicator of exposure to TCE in underground water, we found a dose-dependent positively with NAG levels. 


\section{IMPACT OF OCCUPATION ON BLOOD LEAD LEVELS IN PREGNANT WOMEN}

Osmel La Llave Leon, José Manuel Salas Pacheco, Sergio Estrada Martínez, Ada Sandoval Carrillo, Angélica Ma Lechuga Quiñones, Eloísa Esquivel Rodríguez, Gonzalo García Vargas. Universidad Juárez Del Estado de Durango, Durango, Mexico

\subsection{6/oemed-2014-102362.286}

Objectives To examine the relationship between occupation and blood lead levels in pregnant women of Durango, Mexico. Method A cross sectional study was conducted with 299 pregnant women. Information on occupation, risk factors and sociodemographic data was collected by means of a structured questionnaire. Blood lead concentration was tested by graphite furnace spectrometry. Women were divided into three groups according to occupation: working in places with potential source of lead exposure (exposed group), working in places without lead exposure (control group I), and non-working women (control group II). The $\mathrm{X}^{2}$ test was used to assess statistical differences between the groups, and one way ANOVA was applied for comparisons. Logistic regression was performed using blood lead $<5 \mu \mathrm{g} / \mathrm{dL}$ or $\geq 5 \mu \mathrm{g} / \mathrm{dL}$ as dependent variable, and ajdusted for jurisdiction, income, gestational age, and abortions.

Results Only 24(8\%) women worked in places with potential source of lead exposure, $47(15.7 \%)$ worked in other places, and $228(76.3 \%)$ did not have a remunerated job. Mean blood lead concentration in the study sample was $2.79 \mu \mathrm{g} / \mathrm{dL}$. However, blood lead $\geq 5 \mu \mathrm{g} / \mathrm{dL}$ accounted for $25 \%$ of exposed women, $2.1 \%$ of control group I, and $6 \%$ of control group II $\left(\mathrm{X}^{2}=\right.$ 13.04; p .001). Mean blood lead level was $4.24 \mu \mathrm{g} / \mathrm{dL}$ in the exposed group, $2.31 \mu \mathrm{g} / \mathrm{dL}$ in the control group I, and $2.74 \mu \mathrm{g} /$ $\mathrm{dL}$ in the control group $\mathrm{II}$; those differences were statistically significant (0.001). Logistic regression confirmed that blood lead $\geq 5 \mu \mathrm{g} / \mathrm{dL}$ is associated with occupational exposure $(\mathrm{p}=0.036)$. Conclusions Our findings suggest that surveillance for occupational exposure to prevent health damages during pregnancy is needed.

\section{SCREENING AND DISABILITY PREVENTION FOR MUSCULOSKELETAL DISORDERS OF HIGH-TECH INDUSTRY WORKERS IN TAIWAN}

Ya-Yuan Hsu. Institute of Occupational Safety and Health, Taipei, Taiwan

10.1136/oemed-2014-102362.287

Objectives In Taiwan, 40-60\% of the working population is affected by musculoskelet al disorders (MSD). MSD may lead to reduced productivity, decreased work ability, and even disability. The aim of this study was to describe the effects about occupational health medical team preventing and management of MSD. Method The design was prospective study describing the hightech industry workers screening and disability prevention for MSD. The quantitative analysis of the questionnaire was conducted through descriptive statistics and pair- $t$ test in order to indicate the direction and relationship between the two sets of occupational health medical team intervention program.

Results Of the 386 high-tech industry workers who completed the questionnaire. The use of pair-t test comparing two months of occupational health medical program, individual symptom scores significantly decreased 1.99 points to 6.12 points. The degree of functional subjects increased from $57 \%$ to $74 \%$, a significant improvement. Work ability index before treatment was 38.49 to 39.36 points after treatment improved, particularly in the self-evaluation and self-ability and physical work / effort needs very significant improvement in symptoms improve work ability index, increased efficiency and productivity. Subjects original degree of disability is about $22.33 \%$, significantly decreased to $18.1 \%$ after treatment.

Conclusions Early worksite screening and intervention for MSDs performed by occupational health medical team intervention program were effective on improving the work ability and the functional level. This service may also prevent worsening of the MSDs, and lead to significant reductions in occupational disorders, decreased health care costs, and improvements in production efficiency.

\section{WEEKEND WORK AND PSYCHOSOCIAL WELL-BEING IN KOREAN WORKERS}

${ }^{1}$ Hye-Eun Lee, ${ }^{1}$ Hyoung-Ryoul Kim, ${ }^{2}$ In-Ah Kim. ${ }^{1}$ Department of Occupational and Environmental Medicine, College of Medicine, The Catholic University of Korea, Seoul, Republic of Korea; ${ }^{2}$ Graduate School of Public Health, Yonsei University, Seoul, Republic of Korea

\subsection{6/oemed-2014-102362.288}

Objectives To identify association between weekend work and psychosocial well-being in a representative sample of Korean workers.

Method We analysed the associations between weekend work and psychosocial well-being in 29711 workers using data from the 2011 Korean Working Conditions Survey. Weekend work was defined by working one or more day on Saturday or on Sunday over the last month. Psychosocial well-being was measured by WHO well-being index. Multiple logistic regression analysis was performed adjusting age, education, income, regular/non-regular work, working time with stratifying sex and shift-work.

Results The prevalence of weekend work was higher in male $(62.4 \%)$ than in female $(54.8 \%)$. The longer working time per week, the more employees worked weekend $[<40$ (42.6\%), 40-48 (45.3\%), 49-60 (80.6\%), $\geq 61$ (94.9\%)]. Shift workers (87.3\%) worked more than non-shift workers $(56.2 \%)$ on weekend. In non-shift workers, weekend work group ( $\leq 4$ days) $[\mathrm{OR}=1.34$ (95\% CI 1.22-1.48), OR=1.17 (95\% CI 1.05-1.31)]and weekend work group ( $>4$ days) $[\mathrm{OR}=1.19$ (95\% CI 1.03-1.38), OR=1.30 (95\% CI 1.10-1.52)] were significant risk factors associated with lesser psychosocial well-being in male and female respectively.

Conclusions Weekend work is associated with a significant increase in lesser psychosocial well-being among Korean nonshift workers.

\section{EVALUATION OF SHIFT FATIGUE AND PHYSICAL HEALTH INTERVENTION IN PAPER MANUFACTURER OF WORKERS}

Ya-Yuan Hsu. Institute of Occupational Safety and Health, Taipei, Taiwan

10.1136/oemed-2014-102362.289

Objectives Shift and fatigue is one the most easily neglected health issues in occupation safety. The purposes of the study were to develop convenient method to evaluate the sources of fatigue in worksite and develop a physical health promotion program. Method The design was prospective study describing the paper manufacturer workers. Use myoton measuremented muscle stiffness and elasticity. The quantitative analysis of the three 